\title{
An ABC Transporter and a Cytochrome P450 of Nectria haematococca MPVI Are Virulence Factors on Pea and Are the Major Tolerance Mechanisms to the Phytoalexin Pisatin
}

\author{
Jeffrey J. Coleman, Gerard J. White, Marianela Rodriguez-Carres, and Hans D. VanEtten \\ Department of Plant Sciences, Division of Plant Pathology and Microbiology, University of Arizona, Tucson, AZ 85721, U.S.A.
}

Submitted 1 September 2010. Accepted 9 November 2010.

The fungal plant pathogen Nectria haematococca MPVI produces a cytochrome $\mathbf{P 4 5 0}$ that is responsible for detoxifying the phytoalexin pisatin, produced as a defense mechanism by its host, garden pea. In this study, we demonstrate that this fungus also produces a specific ATP-binding cassette $(\mathrm{ABC})$ transporter, $\mathrm{NhABC1}$, that enhances its tolerance to pisatin. In addition, although both mechanisms individually contribute to the tolerance of pisatin and act as host-specific virulence factors, mutations in both genes render the fungus even more sensitive to pisatin and essentially nonpathogenic on pea. $N h A B C 1$ is rapidly induced after treatment with pisatin in vitro and during infection of pea plants. Furthermore, NhABC1 was able to confer tolerance to the phytoalexin rishitin, produced by potato. $N h A B C 1$ appears to be orthologous to $G p A B C 1$ of the potato pathogen Gibberella pulicaris and, along with $M o A B C 1$ from Magnaporthe oryzae, resides in a phylogenetically related clade enriched with $\mathrm{ABC}$ transorters involved in virulence. We propose that $\mathrm{NhABC1}$ and the cytochrome P450 may function in a sequential manner in which the energy expense from pisatin efflux by $\mathrm{NhABC1}$ releases the repression of the cytochrome $\mathbf{P 4 5 0}$, ultimately allowing pisatin tolerance by two mechanisms. These results demonstrate that a successful pathogen has evolved multiple mechanisms to overcome these plant antimicrobial compounds.

In 1940, Müller and Börger (1940) proposed that production of phytoalexins, specific plant antibiotics produced in response to microbial infection, is a major plant resistance mechanism. It was another 20 years before the first phytoalexin, (+) pisatin (Fig. 1) from pea (Pisum sativum L.), was chemically identified (Cruickshank and Perrin 1960). Soon after, in a classic study evaluating the sensitivity of 45 fungal species, Cruickshank (1962) observed that only five species were tolerant of pisatin,

Current address for J. J. Coleman: Harvard Medical School, Massachusetts General Hospital, Division of Infectious Diseases, 55 Fruit Street, Gray Jackson 5, Room GRJ-504, Boston, MA 02114-2696, U.S.A.

Current address for M. Rodriguez-Carres: Department of Biology, Duke University, 125 Science Dr., Durham, NC 27708, U.S.A.

Corresponding author: H. D. VanEtten; Telephone: +1.520.621.9355; Fax: +1.520.621.7186; E-mail: vanetten@ag.arizona.edu

Nucleotide sequence data for $N h A B C 1$ is available from the GenBank database under accession number HM106507. all of which were pathogens of pea. This remarkable correlation demonstrating a linkage between tolerance and host range firmly established the concept that tolerance to phytoalexins could be a host-specific virulence trait (Cruickshank 1965). In 1964 , it was reported that two fungal pea pathogens were capable of degrading pisatin (Uehara 1964). This conclusion was disputed by Cruickshank and Perrin (1965), but they were mislead in their studies because their assay for pisatin did not distinguish between pisatin and the nontoxic demethylated compound produced from pisatin by most pea pathogens (Fig. 1). The enzyme that rapidly catalyzes pisatin detoxification, pisatin demethylase (PDA), is a unique cytochrome P450 restricted primarily to pea pathogens (Delserone et al. 1999; George and VanEtten 2001). PDA has been best studied in Nectria haematococca mating population (MP) VI, in which it is a host-specific virulence factor on pea (Wasmann and VanEtten 1996). The gene (PDAl) encoding this enzyme is clustered with three other genes involved in pea pathogenicity (PEP genes) (Han et al. 2001) on a supernumerary chromosome, a dispensable portion of the genome of this fungus (Miao et al. 1991a). This type of supernumerary chromosome in fungi has been called conditionally dispensable (CD) because these chromosomes contain genes, such as the PEP genes, which allow for growth in some habitats (e.g., pea), but the chromosomes are not required for growth in other natural habitats or in culture (Covert 1998).

Prior studies of $N$. haematococca MPVI in which PDAl was mutated by gene disruption demonstrated that $\triangle P D A 1$ isolates exhibit increased sensitivity to pisatin and reduced virulence on pea (Wasmann and VanEtten 1996). However, these mutants are still pathogenic and fairly tolerant of pisatin when compared with other fungi. Studies using $N$. haematococca MPVI isolates that lack PDA activity demonstrated that a second mechanism for tolerance to pisatin, termed "nondegradative" tolerance, exists and is induced by pisatin and several structurally similar phytoalexins (Denny and VanEtten 1983a and b; Denny et al. 1987). This tolerance mechanism has many of the biochemical features of an efflux transporter, a process that has previously been demonstrated to be involved in fungal virulence on plant hosts (Fleissner et al. 2002; Schoonbeek et al. 2001; Urban et al. 1999). A molecular mechanism responsible for nondegradative tolerance to pisatin was identified in this current study as an ATP-binding cassette (ABC) transporter. This ABC transporter and the cytochrome P450 encoded by $P D A 1$ are the major tolerance mechanisms to pisatin in $N$. haematococca MPVI, and each contributes to the virulence of this fungus on pea. 


\section{RESULTS}

\section{Identification and cloning of $\mathrm{NhABC1}$.}

Previous studies identifying the $N$. haematococca MPVI nondegradative tolerance to pisatin phenomenon demonstrated that this mechanism was induced by subinhibitory concentrations of the phytoalexin within $3 \mathrm{~h}$ (Denny and VanEtten 1983a and $b$ ). To determine if an ABC transporter might be involved in nondegradative tolerance to pisatin, total RNA was isolated from pisatin-treated mycelia of $N$. haematococca and was subjected to reverse transcription- polymerase chain reaction (RTPCR), using degenerate primers designed to amplify transcripts for ABC transporters. Eleven cloned PCR products were selected for sequencing and seven of these sequences corresponded to a single $\mathrm{ABC}$ transporter, while the other four sequences were of two other ABC transporters. Quantitative PCR was used to confirm the induction of these transporters by pisatin. In vitro induction of the $\mathrm{ABC}$ transporter corresponding to the most common cloned sequence was rapid and evident within $10 \mathrm{~min}$ after treatment with pisatin $(90 \mu \mathrm{g} / \mathrm{ml})$, increasing approximately 220 -fold within $2 \mathrm{~h}$ after treatment (data not shown). The gene encoding this $\mathrm{ABC}$ transporter was designated $N h A B C 1$ and was selected for further analysis.

The $N h A B C 1$ open reading frame (ORF) is $4,528 \mathrm{bp}$ in length, contains a single 47-bp intron, and encodes a protein 1,493 amino acids in length (GenBank accession number HM106507), corresponding to protein 63,187 (Nh63187) in the genome of the isolate of $N$. haematococca MPVI that was recently sequenced (77-13-4). Software topology prediction programs predict 12 transmembrane helices within the protein in a $\left(\mathrm{NBD}-\mathrm{TMD}_{6}\right)_{2}$ topology, placing NhABC1 within the pleiotropic drug resistance (PDR) family of $\mathrm{ABC}$ transporters (Sanwal et al. 2009). Similarity searches to characterized proteins by BLASTp indicated that NhABC1 was closely related to $\mathrm{GpABC} 1$ of the potato pathogen Gibberella pulicaris $(79.6 \%$ amino acid identity and $88.1 \%$ amino acid similarity) and $\mathrm{ABC} 1$ of the rice pathogen Magnaporthe oryzae (57.8\% amino acid identity and $70.8 \%$ amino acid similarity), two ABC transporters that are essential for high virulence for each of these fungi (Fleissner et al. 2002; Urban et al. 1999).

The two genes represented by the other cloned ABC transporter sequences were Nh77470 and Nh67597 in the sequenced N. haematococca MPVI isolate. However, in vitro expression analysis found these genes to be either not induced by pisatin (Nh77470) or the induction was not as high or as rapid as $N h A B C 1$, and they were, therefore, not selected for further molecular characterization.

\section{N. haematococca NhABC1 mutants \\ have increased sensitivity to pisatin.}

In order to investigate the role of $\mathrm{NhABC} 1$ in pisatin tolerance and virulence on pea, gene disruption mutants were generated by homologous gene recombination. At $90 \mu \mathrm{g}$ of $(+)$ pisatin per milliliter, the $\triangle P D A l$ mutant showed a reduction in tolerance of approximately $20 \%$, but the $\triangle N h A B C 1$ mutant showed only a slight reduction in tolerance (approximately 5\%),

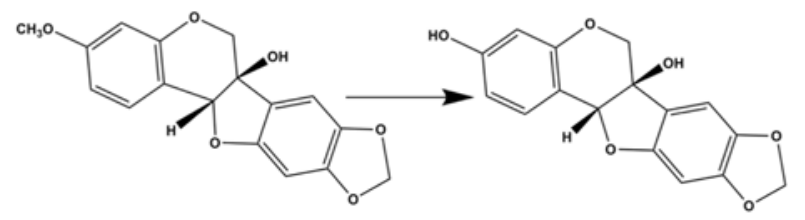

(+) pisatin

(+) 6a-hydroxymaackiain

Fig. 1. Detoxification of $(+)$ pisatin by pisatin demethylase to the less toxic compound (+) 6a-hydroxymaackiain. presumably because the pisatin was removed from the medium by the PDA activity present in the mutant (Fig. 2A).

The potential redundant relationship between $P D A l$ and $N h A B C 1$ requires a double mutant to be generated to accurately access the contribution of $\mathrm{NhABC} 1$ to pisatin tolerance. Mutants of both PDAl and NhABCl were generated through a series of crosses using each of the single mutants of $N$. haematococca MPVI as a parent. The progeny were confirmed for the presence of the $\mathrm{CD}$ chromosome carrying the disrupted $P D A l$ gene as well as the functional $P E P$ genes by the ability of the isolate to utilize homoserine as a carbon source, a trait conferred specifically by this chromosome (Rodriguez-Carres et al. 2008).

Four progeny (375-1, 375-9, 375-13, and 375-19) were identified that carried mutations in both $N h A B C 1$ and $P D A 1$. These double mutants were even more sensitive (collectively averaging approximately $50 \%$ reduction compared with wild type) to pisatin than the $\triangle P D A 1$ mutant, thus demonstrating the effect of $N h A B C l$ (Fig. 2A). The increase in sensitivity to pisatin of the double mutants of $N$. haematococca MPVI is even more evident when isolates are subjected to a higher concentration $(180 \mu \mathrm{g} / \mathrm{ml})$ of pisatin, as growth of the double mutants was reduced by approximately $80 \%$ in comparison with the wild-type isolate with functional copies of PDAl and $N h A B C 1$ (Fig. 2B). Germination of double mutant spores from $375-13$ is also greatly reduced at this concentration of pisatin, in comparison with the wild-type isolate and either single mutant (Table 1). There appears to be a slight lag in spore germination of the mutant with a disrupted copy of NhABC1 as compared with $\triangle P D A l$ spores, suggesting $N h A B C l$ may be more important when the fungus is initially exposed to pisatin. Interestingly, the $\triangle N h A B C 1 ; \triangle P D A 1$ double mutants are more toler-

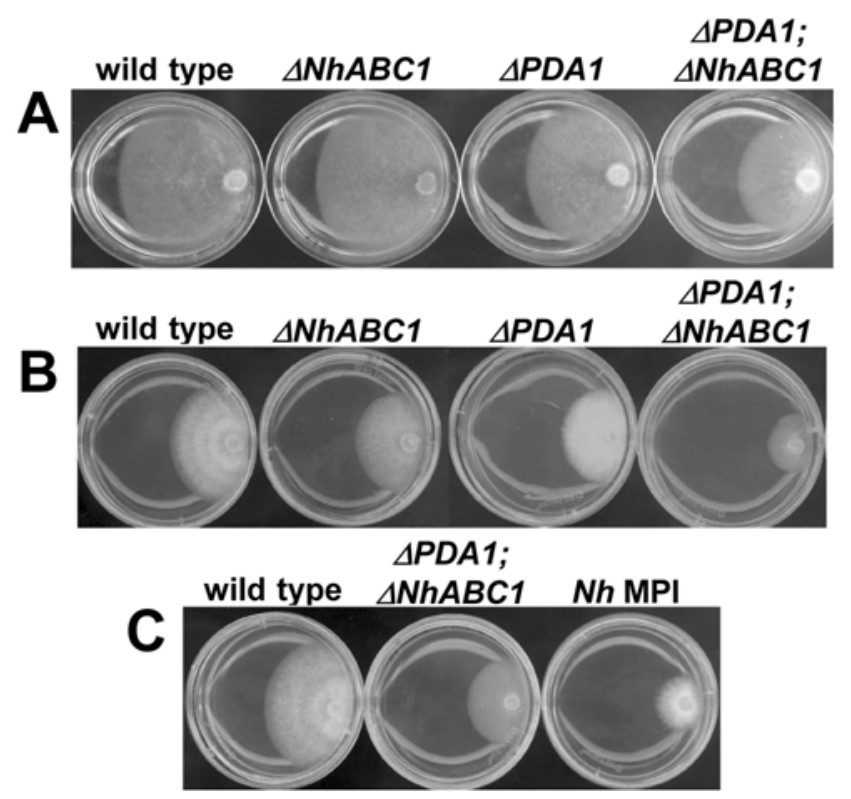

Fig. 2. Pisatin tolerance bioassays of Nectria haematococca isolates. A, Radial growth after 5 days of growth on $90 \mu \mathrm{g}$ of (+) pisatin per milliliter for (left to right) wild type (77-13-7), NhABC1 mutant (Tr8.1), PDA1 mutant (Tr18.5), and a PDA1;NhABC1 double mutant (375-13). All isolates showed the same growth as isolate 77-13-7 on medium lacking pisatin. B, Radial growth on $180 \mu \mathrm{g}$ of (+) pisatin per milliliter for (left to right) wild type (77-13-7), NhABC1 mutant (Tr8.1), PDA1 mutant (Tr18.5), and the $\triangle P D A 1 ; \triangle N h A B C 1$ double mutant (375-13). The NhABC1 mutant, the $P D A 1$ mutant, and the $P D A 1 ; N h A B C 1$ double mutants displayed $87 \pm 8$, $57 \pm 15$, and $22 \pm 11 \%$ of the radial growth of $77-13-7$, respectively. $\mathbf{C}$, Radial growth on $90 \mu \mathrm{g}$ of $(+)$ pisatin per milliliter for (left to right) wild type (77-13-7), a $\triangle P D A 1 ; \triangle N h A B C 1$ double mutant (375-13), and $N$. haematococca MPI (Nh MPI; NRRL 22165), a taxonomically related fungus that is not a pea pathogen. 
ant to pisatin than the closely related fungus $N$. haematococca MPI, which is not a pea pathogen (Fig. 2C) and has been shown to be particularly sensitive to pisatin (VanEtten et al. 1980). This suggests that other pisatin tolerance mechanisms, which have yet to be identified, exist in $N$. haematococca MPVI or that MPI is unusually sensitive to pisatin.

\section{$N h A B C 1$ is a virulence factor for pea.}

PDA1 was previously shown to be a virulence factor on pea, as $N$. haematococca MPVI transformants with this cytochrome P450 mutated produce smaller lesions (Wasmann and VanEtten 1996). Pathogenicity assays performed for the current study demonstrated that $\triangle N h A B C 1$ mutants of $N$. haematococca MPVI were reduced in virulence on pea and produced a lesion similar in size to those produced by PDA1-disrupted mutants (Fig. 3; Table 2). However, isolates lacking both tolerance mechanisms (375-1, 375-9, 375-13, and 375-19) are even further reduced in virulence than either single mutant (Fig. 3; Table 2).

Table 1. Percentage of Nectria haematococca MPVI spores germinating in $(+)$ pisatin $(180 \mu \mathrm{g} / \mathrm{ml})^{\mathrm{a}}$

\begin{tabular}{|c|c|c|c|c|}
\hline Time (h) & $\begin{array}{l}\text { Wild type } \\
(77-13-7)\end{array}$ & $\begin{array}{c}\triangle P D A 1 \\
(\operatorname{Tr} 18.5)\end{array}$ & $\begin{array}{c}\triangle N h A B C 1 \\
(\operatorname{Tr} 8.1)\end{array}$ & $\begin{array}{c}\triangle P D A 1 ; \triangle N h A B C 1 \\
(375-13)\end{array}$ \\
\hline 5 & 10 & 2 & 1 & 0 \\
\hline 8 & 72 & 77 & 68 & 4 \\
\hline 10 & 94 & 92 & 88 & 12 \\
\hline 12 & $>95$ & $>95$ & 93 & 23 \\
\hline 14 & & & 91 & 32 \\
\hline 17 & & & $>95$ & 58 \\
\hline
\end{tabular}

${ }^{a}$ Isolates not receiving pisatin treatment had germinated $>95 \%$ after $10 \mathrm{~h}$.
In planta expression analysis using quantitative PCR shows the expression of both $N h A B C 1$ and $P D A 1$ increase as pisatin accumulates in the plant tissue (Fig. 4). Expression of NhABC1 is initially induced more rapidly than $P D A 1$, suggesting it may be more important in the early stages of tolerance to pisatin than PDA1, but both genes clearly demonstrate enhanced expression during pathogenesis.

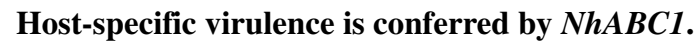

$N$. haematococca MPVI is also pathogenic on carrot, and prior studies showed that the lack of PDA does not affect the

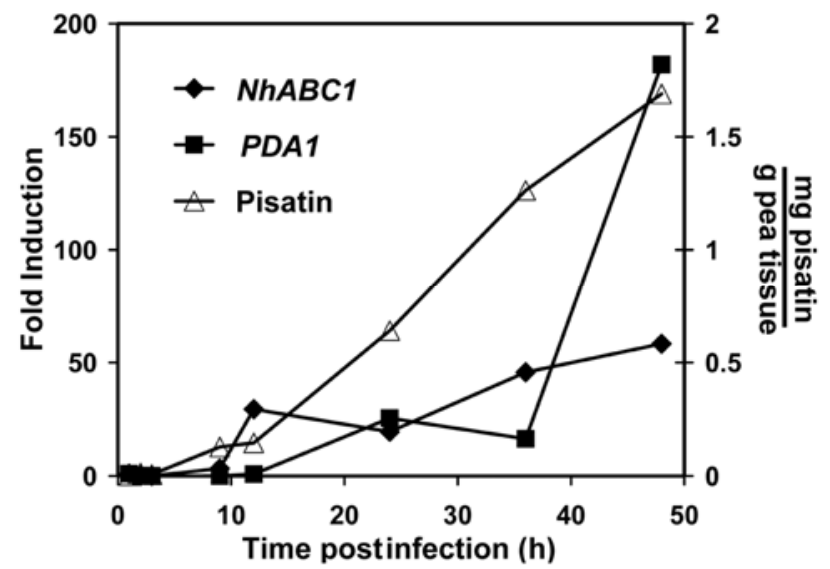

Fig. 4. In planta induction of pisatin tolerance genes in Nectria haematococca MPVI during infection of pea. Fold induction of NhABCl and $P D A 1$ are depicted. Concentration of pisatin (milligrams per gram of pea tissue dry weight) produced in infected pea pods is also shown.

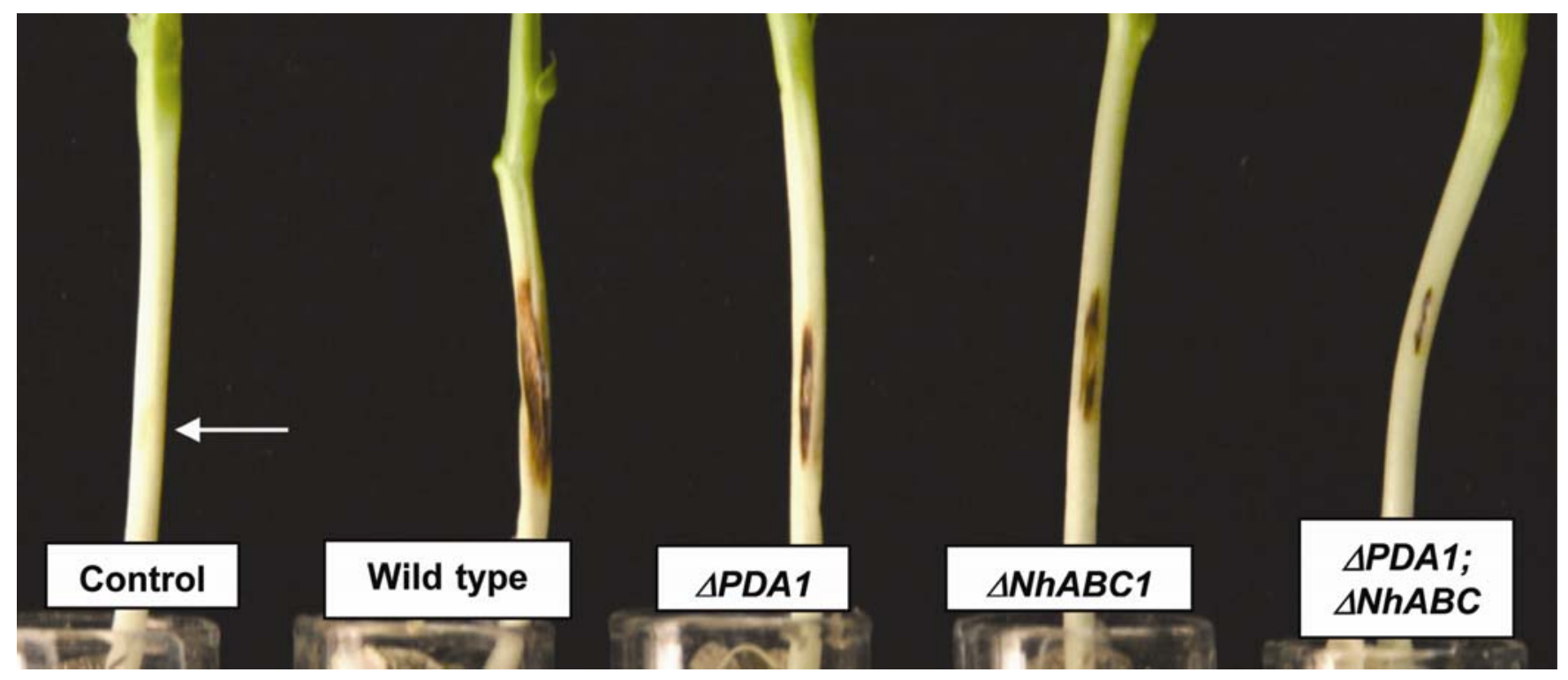

Fig. 3. Lesions produced on garden pea 6 days postinoculation for (left to right) a nonpathogenic isolate (44-100), wild type (77-13-7), $\triangle P D A 1$ mutant (Tr18.5), $\triangle N h A B C 1$ mutant (Tr8.1), and a $\triangle P D A 1 ; \triangle N h A B C 1$ double mutant (375-13). Arrow indicates site of inoculation.

Table 2. Virulence (lesion lengths) of Nectria haematococca MPVI isolates on pea ${ }^{\mathrm{a}}$

\begin{tabular}{|c|c|c|c|c|c|c|c|c|}
\hline \multirow[b]{2}{*}{ Experiment } & \multirow{2}{*}{$\begin{array}{l}\text { Wild type } \\
(77-13-7)\end{array}$} & \multirow{2}{*}{$\begin{array}{c}\text { Negative control } \\
\qquad(44-100)\end{array}$} & \multirow{2}{*}{$\begin{array}{c}\triangle P D A 1 \\
(\operatorname{Tr} 18.5)\end{array}$} & \multirow{2}{*}{$\begin{array}{c}\triangle N h A B C 1 \\
(\operatorname{Tr8.1})\end{array}$} & \multicolumn{4}{|c|}{$\triangle P D A 1, \triangle N h A B C 1$} \\
\hline & & & & & $375-1$ & $375-9$ & $375-13$ & $375-19$ \\
\hline 1 & $14.1 \pm 7.2$ & $2.5 \pm 0.8^{*}$ & $6.1 \pm 2.4^{*}$ & $6.5 \pm 1.7^{*}$ & $4.6 \pm 0.6^{*}, \S$ & $4.7 \pm 0.6^{*, 8}$ & $3.7 \pm 0.8^{*}, 8$ & $3.4 \pm 0.6^{*}, 8$ \\
\hline 2 & $18.8 \pm 2.9$ & $3.0 \pm 1.3^{*}$ & $13.4 \pm 2.3^{*}$ & $12.1 \pm 4.5^{*}$ & $6.7 \pm 3.0^{*}, \S$ & $4.7 \pm 1.0^{*, 8}$ & $6.1 \pm 2.3^{*, 8}$ & $7.1 \pm 2.3^{*, 8}$ \\
\hline 3 & $13.9 \pm 4.0$ & $3.2 \pm 0.9^{*}$ & $8.5 \pm 3.0^{*}$ & $5.3 \pm 1.3^{*}$ & $3.7 \pm 1.8^{*, 8}$ & $4.0 \pm 1.0^{*, 8}$ & $3.1 \pm 1.5^{*}, \S$ & $3.4 \pm 1.3^{*}, \S$ \\
\hline 4 & $13.1 \pm 4.2$ & $3.8 \pm 0.8^{*}$ & $6.4 \pm 2.2^{*}$ & $10.2 \pm 3.1^{*}$ & & & $3.8 \pm 0.8^{*}, \S$ & $5.4 \pm 0.8^{*}, \#$ \\
\hline
\end{tabular}

${ }^{a}$ Lesion sizes are in millimeters and are based on eight to 10 plants per treatment per experiment. Superscript symbols indicate lesion size is significantly different $(P \leq 0.05)$ compared with 77-13-7 (*), Tr8.1 ( $\triangle N h A B C 1)(\#)$, or both single mutants $(\S)$. 
virulence of this fungus on that host (Funnell and VanEtten 2002; Wasmann and VanEtten 1996). Pathogenicity assays again demonstrate that a $\triangle P D A 1$ mutant is not reduced in virulence on carrot, and the $\triangle N h A B C l$ mutant and the $\triangle N h A B C l$; $\triangle P D A 1$ double mutant also were not reduced in virulence, indicating that the virulence provided by $P D A l$ and $N h A B C l$ are each specific for pathogenicity on garden pea (Fig. 5).

To determine if $N h A B C l$ is found only in N. haematococca MPVI isolates that are pathogenic on pea, Southern hybridizations were conducted to assess the distribution of the $\mathrm{ABC}$ transporter among various fungi. All twelve N. haematococca MPVI isolates included in the analysis had genomic fragments hybridizing to $N h A B C 1$, including isolates with different degrees of virulence on pea from laboratory crosses (34-18, 2125-1, 212-1-4, 312-2-5, 352-B-10, 230-30-6, and 44-100) and four field isolates from geographically diverse locations (T-23 from New York, T-110 from Mississippi, T-288 from South Carolina, and T-406 from Taiwan), including two field isolates that are not pathogenic on pea (T-110 from cottonwood and T288 from soil) (Miao et al. 1991b) (Fig. 6).

Analysis of the distribution of $N h A B C 1$ was further extended to fungi besides $N$. haematococca MPVI. Southern hybridization revealed that homologs of $N h A B C 1$ exist in the phylogenetically related fungi Neocosmospora vasinfectia, Neocosmospora boniensis [Neocosmospora boninensis], and $N$. haematococca MPI. However, there was no hybridization to genomic DNA from other pea pathogens, including Ascochyta pisi, Colletotrichum pisi, Mycosphaerella pinodes, Phoma pi-

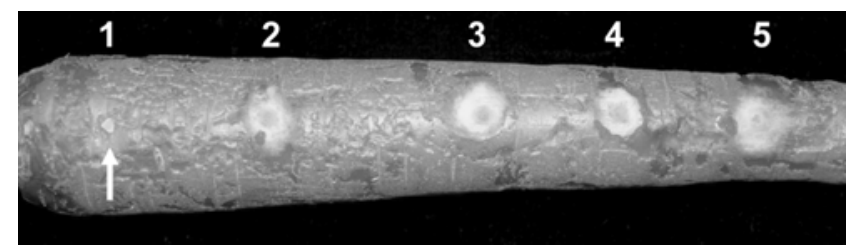

Fig. 5. Virulence of Nectria haematococca MPVI isolates on carrot, 7 days postinoculation with the following isolates. 1, N. haematococca MPI (nonpathogenic isolate, indicated by arrow), 2, wild type (77-13-7), 3, PDA1 mutant (Tr18.5 ), 4, NhABC1 mutant (Tr8.1), and 5, PDA1;NhABC1 double mutant (375-13). nodella, or the phylogenetically related pea pathogen included in this study, Fusarium oxysporum f. sp. pisi. Homologs of $N h A B C l$ were also not identified in fungi pathogenic on plants other than pea, such as the corn pathogen Cochliobolus heterostrophus, the rice pathogen $M$. oryzae, the sorghum pathogens Gloeocerospora sorghi and Colletotrichum graminicola, the wheat pathogen Gaeumannomyces graminis var. tritici, or the saprophytic fungi Neurospora crassa and Aspergillus nidulans (Fig. 6).

\section{The specificity of the tolerance conferred to $N$. haematococca by NhABC1.}

The NhABCl mutant was tested for a change in sensitivity to 45 antimicrobial chemicals, including both natural and synthetic compounds. The NhABCl mutant demonstrated an increase in sensitivity to only three of these compounds, (+) pisatin, the stereoisomer $(-)$ pisatin, and the potato phytoalexin rishitin (Fig. 7).

\section{NhABC1 is phylogenetically related} to other $\mathrm{ABC}$ transporters involved in virulence.

$N h A B C 1$ is homologous ( $87 \%$ similar at the amino acid level) to $G p A B C 1$ from $G$. pulicaris, which was previously shown to

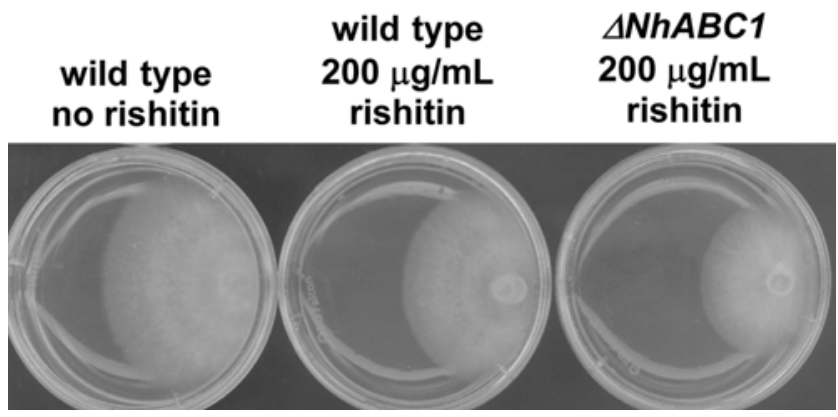

Fig. 7. Radial growth of Nectria haematococca MPVI on the potato phytoalexin rishitin. Left to right: wild type (77-13-7), no rishitin); wild type (77-13-7), with $200 \mu \mathrm{g}$ of rishitin per milliliter, approximately $25 \%$ inhibition; and the NhABC1 mutant (Tr8.1), with $200 \mu \mathrm{g}$ of rishitin per milliliter, approximately $45 \%$ inhibition as compared with the wild-type isolate containing no rishitin.

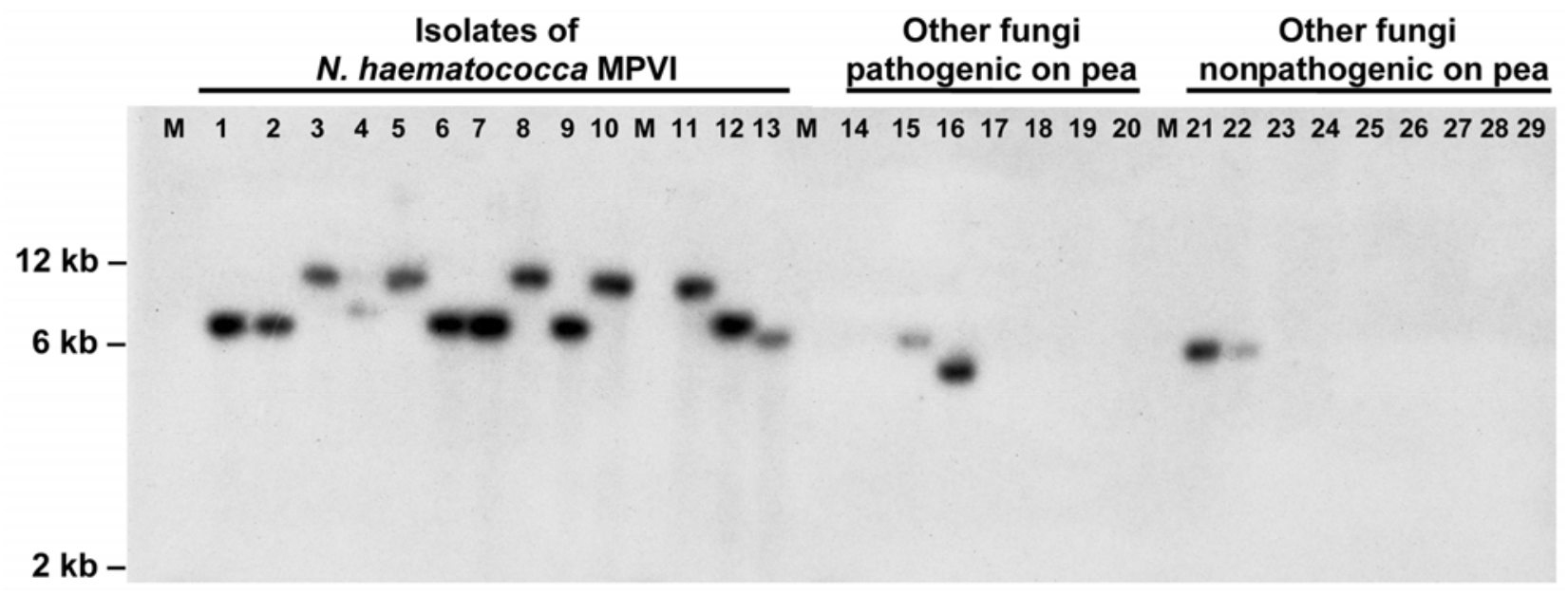

Fig. 6. Distribution of the $N h A B C 1$ homologs among various fungal isolates. A probe corresponding to NhABC1 from Nectria haematococca MPVI isolate 77-13-7 was hybridized to EcoRI-digested genomic DNA. Twelve N. haematococca MPVI isolates (77-13-7, 77-13-7 Tr18.5 [ $\triangle P D A 1$ transformant], 34-18, T-23, T-406, 212-5-1, 212-1-4, 312-2-5, 352-B-10, 230-30-6, T-110, T-288, and 44-100, lanes 1 to 13 respectively), seven other pea pathogenic fungi (Fusarium oxysporum f. sp. pisi, Neocosmospora vasinfecta, Neocosmospora bonniensis, Phoma pinodella, Colletotrichum pisi, Mycosphaerella pinodes, and Ascochyta pisi, lanes 14 to 20), and nine fungi not pathogenic on pea (N. haematococca MPI NRRL 22153, N. haematococca MPI NRRL 22165, Cochliobolus heterostrophus, Magnaporthe oryzae, Colletotrichum graminicola, Gloeocerospora sorghi, Gaeumannomyces graminis var. tritici, Neurospora crassa, and Aspergillus nidulans, lanes 21 to 29) were subjected to the analysis. M denotes lanes containing the DNA ladder. No hybridization fragments less than 2 $\mathrm{kb}$ in size were present for any isolate. 
be required for tolerance to the potato phytoalexin rishitin and virulence on potato tubers (Fleissner et al. 2002). These two transporters belong to a monophyletic clade of the PDR family that includes several additional transporters from other phytopathogenic fungi (Fig. 8). The fact that NhABC1 and GpABC1 are phylogenetically within the same clade and both provide tolerance to the phytoalexin rishitin suggests they may be functionally orthologous. This ABC transporter appears to have been vertically inherited, as orthologs of $N h A B C 1 / G p A B C 1$ are phylogenetically conserved in the genomes of the other sequenced Fusarium spp. (Fig. 8). However, the role of the other orthologs in virulence on one or more of their respective host plants has not been reported.

Although ABC transporters of the PDR family usually have little phylogenetic conservation (Coleman and Mylonakis 2009; Kovalchuk and Driessen 2010), a relatively well-conserved sister clade exists that contains $M$. oryzae $\mathrm{ABC} 1$, a virulence factor for rice (Urban et al. 1999). The $N$. haematococca MPVI genome-sequencing project revealed two other closely related ABC transporters (Nh82055 and Nh35467) present in the genome that are homologous to NhABCl (Fig. 8) (Coleman et al. 2009). These two transporters are more phylogenetically related to $M o A B C 1$ (MGG_13624.5 in the sequenced $M$. oryzae isolate 70-15) than to $N h A B C 1$, in which Nh35467 appears to be orthologous to MoABC1 (Fig. 8). However, a sequenced cDNA library constructed from pisatintreated mycelia as part of the $N$. haematococca MPVI genome analysis contained no transcripts corresponding to the genes encoding either Nh82055 or Nh35467, suggesting they are not induced by pisatin.

\section{DISCUSSION}

The molecular arms race between plant hosts and their associated pathogens has been well documented, revealing most successful necrotrophic plant pathogens have evolved mecha-

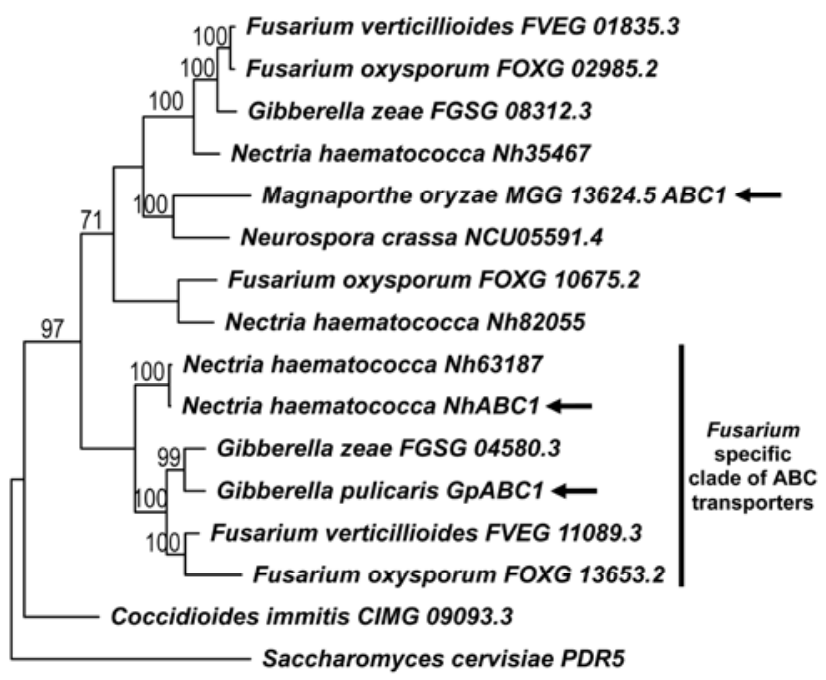

\section{- 100 changes}

Fig. 8. Phylogenetic analysis of a select group of pleiotropic drug resistance transporters from fungi. Maximum parsimony trees were generated, and statistical support was calculated based on 1,000 bootstrap replicates. Arrows indicate $\mathrm{ATP}$-binding cassette $(\mathrm{ABC})$ transporters involved in pathogenicity. NhABC1 from Nectria haematococca MPVI isolate 77-13-7, Nh63187 from $N$. haematococca MPVI isolate 77-13-4, and GpABC1 from Gibberella pulicaris are evolutionarily and functionally orthologous and are part of a monophyletic cluster that appears to be present only in the genome of other fusaria (designated by the black vertical line). nisms to overcome the phytoalexins produced by their host plants (Morrissey and Osbourn 1999; VanEtten et al. 2001). The two proteins responsible for the main tolerance mechanisms to pisatin in $N$. haematococca MPVI represent two different ways to achieve phytoalexin tolerance. ABC transporters confer tolerance by efflux of the compounds across the membrane, thereby preventing an increase in intracellular concentration of the toxic compound (Higgins 2007), and this appears to be the basis of the nondegradative tolerance to pisatin observed in $N$. haematococca MPVI by Denny and VanEtten (1983a and b). Thus, it is presumed that this is the function of NhABC1 in conferring tolerance, whereas the cytochrome $\mathrm{P} 450$ provides tolerance by detoxifying pisatin to the less-toxic compound 6a-hydroxymaackiain (Denny and VanEtten 1981).

The expression in planta of both NhABC1 and PDAl and the effects on virulence on pea and carrot when each is mutated demonstrate that these are host-specific virulence factors and that these proteins act collaboratively to confer tolerance of pisatin in $N$. haematococca MPVI. However, the observed "lag" in spore germination of the NhABC1 mutant when compared with either the wild type or the $P D A 1$ mutant isolates (Table 1) could mean that $N h A B C l$ is particularly important in conferring tolerance during the initial interaction with pisatin. As $\mathrm{ABC}$ transporters are primary transporters, NhABC1 hydrolyzes ATP to transport pisatin across the membrane and out of the fungal cell. However, after it is exported, pisatin is capable of reentering the fungal cell, in which it is again removed by $\mathrm{NhABC} 1$. This tolerance mechanism requires constant hydrolysis of ATP and is a metabolic expense for the cell. Interestingly, the expression of PDAl in N. haematococca MPVI is glucose-repressed (VanEtten and Barz 1981). Therefore, a model of sequential tolerance mechanisms conferring pisatin tolerance in $N$. haematococca MPVI can be proposed. In response to fungal infection, pisatin is synthesized by plant cells and enters the fungal cells. Once the fungus senses pisatin, $N h A B C 1$ is induced and the corresponding protein transports the pisatin out of the fungal cell. The cycle of pisatin entering the fungal cell followed by active efflux causes a drop in ATP and, potentially, a subsequent decrease in intracellular glucose. The glucose repression of PDAl then ceases, allowing PDA1 to be synthesized for enzymatic detoxification of pisatin.

Stemphylium loti, a phytopathogenic fungus of a cyanogenic plant (Lotus corniculatus L.), also appears to have a sequence of tolerance mechanisms that allows the fungus to overcome the toxic effects of cyanide released by its host (Rissler and Miller 1977). Upon exposure to hydrogen cyanide, the inhibition of the fungal cytochrome-based respiration activates a cyanide-insensitive respiratory system. This system allows the fungus to produce enough energy to synthesize a second tolerance mechanism, formamide hydrolyase (cyanide hydratase), which is responsible for enzymatic detoxification of cyanide to the much-less toxic compound formamide.

The enrichment of transporters involved in virulence or tolerance, or both, to phytoalexins within the Fusarium-specific (NhABC1 and GpABC1) clades and phylogenetically related clades containing $\mathrm{ABC} 1$ suggests that their function may have been retained from a common ancestor and that other transporters within these clades may be virulence factors for other phytopathogenic fungi. Hybridization studies identified homologs of $N h A B C 1$ in all phylogenetically related members of the Fusarium solani species complex that were analyzed but were not present in other fungi, regardless of whether they were pathogenic on pea or not. The results indicate that taxonomic relatedness was a better predictor of the presence of a $N h A B C 1$ homolog than was pathogenicity on pea. Furthermore, not all of the homologs detected by hybridi- 
zation studies conferred tolerance to pisatin, as a homolog was detected in $N$. haematococca MPI, a fungus that is very sensitive to pisatin (Fig. 2C).

The observation that $N A A B C l$ is on a larger chromosome (chromosome 8, $3.39 \mathrm{Mb}$ ) in $N$. haematococca MPVI rather than a small $\mathrm{CD}$ chromosome (approximately $1.6 \mathrm{Mb}$ to 500 kb) (Coleman et al. 2009) is also consistent with it arising by vertical evolution rather than by horizontal gene transfer (HGT), a process postulated to have given rise to the CD chromosome. Despite $N h A B C 1$ being vertically inherited and PDAl apparently being acquired by HGT, these two genes appear to have evolved in a sequential manner to function as the major mechanisms responsible for conferring pisatin tolerance in N. haematococca MPVI.

The best-characterized fungal efflux transporter, i.e., PDR5 of Saccharomyces cerevisiae, has a broad and structurally diverse substrate range, whereas $\mathrm{NhABC1}$ appears to transport only a few specific plant-produced antimicrobial compounds. Interestingly, the identified substrates of NhABC1-rishitin, a norsequiterpene alcohol, and pisatin, a pterocarpan-have little structural similarity, although both are phytoalexins. It should be noted that the $N$. haematococca genome encodes 67 ABC transporters (Coleman et al. 2009), and it is possible that other redundant tolerance mechanisms may exist in the fungus, making the true substrate range of $\mathrm{NhABC} 1$ difficult to determine. This is exemplified by the redundant function of NhABC1 and PDA1, whereby the role of the $\mathrm{ABC}$ transporter in pisatin tolerance is not evident in the $\triangle N h A B C l$ isolate but becomes apparent in the $\triangle N h A B C 1 ; \triangle P D A 1$ mutant (Fig. 2). In addition to members of the PDR family of ABC transporters, members of the multidrug resistance (MDR) family and multidrug resistance-associated protein (MRP) family are also known to confer tolerance to toxic compounds (Coleman and Mylonakis 2009). The genome of $N$. haematococca MPVI encodes 22 MDR transporters, 17 MRP transporters, and 23 PDR transporters, in addition to NhABC1 (Coleman et al. 2009).

Several other fungal plant pathogens are reported to have two phytoalexin tolerance mechanisms, although none of these pathogens have had both mechanisms molecularly characterized and evaluated as virulence traits (Morrissey and Osbourn 1999; Pedras and Ahiahoun 2005; VanEtten et al. 2001). The phytopathogen Botrytis cinerea, the causal agent of gray mold on grapevine, encodes an $\mathrm{ABC}$ transporter, BcatrB, and a laccase-like stilbene oxidase, which are able to provide some tolerance to the grapevine phytoalexin resveratrol (Pezet et al. 1991; Schoonbeek et al. 2001). In addition to GpABC1, $G$. pulicaris is capable of metabolizing rishitin, a trait that is linked to a high degree of virulence on potato tubers (Desjardins and Gardner 1989).

This additional data with $N$. haematococca MPVI clearly supports the hypothesis that fungal pathogens have evolved specific drug-resistance mechanisms and that they collectively contribute to a higher level of resistance to host toxins and higher virulence on their host. Furthermore, it shows that although phytoalexin production does provide a defense against pathogen attack in some instances, the most successful plant pathogens may have several tolerance mechanisms to overcome these antimicrobial compounds.

\section{MATERIALS AND METHODS}

\section{Fungal strains, media, and growth conditions.}

All isolates of $N$. haematococca MPI and MPVI were maintained and allowed to sporulate on V8 juice agar medium (Stevens 1974). To obtain mycelium for genomic DNA, $100 \mathrm{ml}$ of potato dextrose broth (PDB) (Becton, Dickinson and Co., Sparks, MD, U.S.A.), contained in 250-ml Erlenmeyer flasks, were inoculated with approximately $10^{5}$ conidia per milliliter and were shaken at $180 \mathrm{rpm}$ for 48 to $72 \mathrm{~h}$ at room temperature.

Genomic DNA was obtained from laboratory stocks for the rest of the isolates, Neocosmospora vasinfecta (ATCC 32302), Neocosmospora boninensis (NRRL 22470), N. haematococca MPI (NRRL 22153; NRRL 22165), Fusarium oxysporum f. sp. pisi (T415), Ascochyta pisi (T422), Colletotrichum pisi (T403), Mycosphaerella pinodes (T414), Phoma pinodella (T409), M. oryzae (Guy11), Cochliobolus heterostrophus (C5), Colletotrichum graminicola (T438), Gloeocerospora sorghi (T442), Gaeumannomyces graminis var. tritici, Neurospora crassa (74-OR8-1a), and Aspergillus nidulans (A4).

\section{Cloning of $\mathrm{NhABC1}$.}

An overnight culture of $\operatorname{Tr} 18.5$, a $\mathrm{PDA}^{-}$transformant of isolate 77-13-7 (Wasmann and VanEtten 1996), was grown in 100 $\mathrm{ml}$ of PDB under the same conditions as above and was treated with a solution of $(+)$ pisatin in dimethyl sulfoxide (DMSO) to give a final concentration of $180 \mu \mathrm{g}$ of $(+)$ pisatin per milliliter and $1.5 \%$ DMSO. The culture was incubated under the same growth conditions for $60 \mathrm{~min}$, and the mycelium was collected by filtration on Whatman \#4 filter paper (Whatman International Ltd., Maidstone, U.K.). Total RNA was extracted using Trizol (Invitrogen Life Technologies, Carlsbad, CA, U.S.A.), and cDNA was synthesized using Superscript II reverse transcriptase (Invitrogen Life Technologies) and oligo dT primer (Invitrogen Life Technologies), following the manufacturer's protocols. The cDNA was used for RT-PCR with degenerate primers designed for conserved regions of $\mathrm{ABC}$ transporters GAGKTT-F (5'-GGI GCN GGN AAR ACN AC-3') and TIHQP-R (5'-GGY TGR TGD ATN GT-3'), with an annealing temperature of $48^{\circ} \mathrm{C}$.

The resulting approximately 500-bp PCR product was excised from the gel and was cloned into pCR2.1, using the TA cloning kit (Invitrogen Life Technologies). The cloned 500-bp PCR fragment of $N h A B C l$ was used as a probe to screen a genomic cosmid library of isolate 77-13-7, and cosmid 70-F6 was shown to contain the gene of interest. A 4-kb EcoRI/HindIII fragment containing the $3^{\prime}$ end of the gene was subcloned into pBluescript (Stratagene, Cedar Creek, TX, U.S.A.) and was sequenced. The remaining portion of $N h A B C 1$ was sequenced directly from the cosmid.

\section{Construction of disruption vector and transformation.}

The approximately $2.3-\mathrm{kb}$ region upstream of the coding region $N h A B C 1$ in cosmid 70-F6 was amplified by PCR, using primers containing unique XhoI and HindIII sites (5'-AAc tcg agA AGT ACG TCC AAG CGC CAT C-3' and 5'-TTa agc ttT TTG ATC AAG ACA GAT GCT GTC C-3') and an annealing temperature of $58^{\circ} \mathrm{C}$. The resulting PCR product was cloned into pBluescript that had the SalI site removed. The 4-kb EcoRI/HindIII fragment from cosmid 70-F6 was then cloned into the vector and the hygromycin-resistance cassette from pCWHyg1 (Wasmann and VanEtten 1996) was cloned into the HindIII site to generate $\mathrm{p} \triangle \mathrm{NhABC} 1$.

Preparation of protoplasts was carried out as follows. Spores $\left(10^{5} \mathrm{ml}^{-1}\right)$ were inoculated into $100 \mathrm{ml}$ of PDB in a $250-\mathrm{ml}$ Erlenmeyer flask and were incubated at room temperature for 16 to $18 \mathrm{~h}$ on a rotary shaker at $180 \mathrm{rpm}$. The mycelium was collected on Whatman \#4 filter paper by vacuum filtration, and $1 \mathrm{~g}$ was suspended in $15 \mathrm{ml}$ of $0.7 \mathrm{M} \mathrm{NaCl}$ with $6 \mathrm{mg}$ of Kitalase per milliliter (Wako Pure Chemical Industries, Ltd., Osaka, Japan) and $5 \mathrm{mg}$ of Driselase (InterSpex Products, Inc., San Mateo, CA, U.S.A.) per milliliter. The mycelia-enzyme suspension was incubated at room temperature for $2 \mathrm{~h}$ on a rotary shaker at $50 \mathrm{rpm}$, and the resulting protoplasts were filtered through Nitex Nylon mesh (40 $\mu \mathrm{m}$, TETCO No. 3-40/26) 
and were collected by centrifugation at $1,000 \times g$ for $10 \mathrm{~min}$. The protoplasts were washed once in $10 \mathrm{ml}$ of $0.7 \mathrm{M} \mathrm{NaCl}$ and once in $10 \mathrm{ml}$ of SuTC (20\% sucrose, $50 \mathrm{mM}$ Tris, $\mathrm{pH} \mathrm{7,50}$ $\mathrm{mM} \mathrm{CaCl} 2$ ) and were suspended in SuTC at a final concentration of $10^{7}$ protoplasts per milliliter.

Transformation was carried out as follows. Protoplast suspension $(100 \mu \mathrm{l})$ was mixed with $12 \mu \mathrm{g}$ of transforming DNA ( $\mathrm{p} \triangle \mathrm{NhABC} 1)$ and was incubated on ice for $15 \mathrm{~min}$. PSTC (1 $\mathrm{ml} ; 60 \%$ polyethylene glycol, molecular weight 3,350, $20 \%$ sucrose, $50 \mathrm{mM}$ Tris, $\mathrm{pH} 7,50 \mathrm{mM} \mathrm{CaCl}_{2}$ ) was added to the protoplasts, which were mixed gently and were incubated at room temperature for $20 \mathrm{~min}$. TB3 ( $3 \mathrm{ml} ; 20 \%$ sucrose, $1 \%$ glucose, $0.3 \%$ yeast extract, $0.3 \%$ casamino acids) were added, and the protoplasts were allowed to regenerate by gentle rocking on a platform shaker at room temperature for 18 to $20 \mathrm{~h}$. The regenerated mycelium was collected by centrifugation at $3,000 \times g$, was suspended in $100 \mu \mathrm{l}$ of SuTC, was mixed with $8 \mathrm{ml}$ of regeneration top agarose $(20 \%$ sucrose, $1 \%$ glucose, $1 \%$ yeast extract, $1 \%$ casamino acids, $1.5 \%$ agarose), and was poured into petri plates containing $20 \mathrm{ml}$ potato dextrose agar with $60 \mu \mathrm{g} / \mathrm{ml}$ hygromycin B (Calbiochem, La Jolla, CA, U.S.A.). Hygromycin-resistant colonies were visible after 4 to 7 days and were transferred to petri plates containing M-100 medium (Stevens 1974) with $60 \mu \mathrm{g}$ of hygromycin per milliliter.

Hygromycin-resistant isolates were screened for disruption of $N h A B C 1$ by Southern blotting. DNA was extracted as previously described (Miao et al. 1991b) and was digested with ClaI. The DNA was transferred to Hybond TM-N+ membrane (Amersham Pharmacia Biotech, Ltd, Buckinghamshire, U.K.) and was hybridized with a ${ }^{32} \mathrm{P}-$ labeled 668-bp XbaI/SpeI fragment upstream of $N h A B C 1$. The membrane was washed at $65^{\circ} \mathrm{C}$ in a series of solutions: once in $2 \times \mathrm{SSC}(1 \times \mathrm{SSC}$ is 0.15 $\mathrm{M} \mathrm{NaCl}$ plus $0.015 \mathrm{M}$ sodium citrate), $0.1 \%$ sodium dodecyl sulfate (SDS) for $20 \mathrm{~min}$ (low stringency), twice in $1 \times \mathrm{SSC}$, $0.1 \%$ SDS for $20 \mathrm{~min}$ (medium stringency), and twice in $0.1 \times$ SSC, $0.1 \%$ SDS for $20 \mathrm{~min}$ (high stringency). The NhABC1 mutant (Tr8.1) was identified by the smaller size of the hybridizing DNA fragment and an absence of the corresponding wild type-size hybridizing fragment.

\section{Crosses to generate a double mutant.}

Crosses of $N$. haematococca isolates were conducted as described by Kistler and VanEtten (1984) to yield isolates with mutations in both $P D A 1$ and $N h A B C 1$. Since the transformants with disrupted genes $(\operatorname{Tr} 8.1, \triangle N h A B C 1 ; \operatorname{Tr} 18.5, \triangle P D A 1)$ were made using the same isolate (77-13-7, mat1) and this fungus is heterothallic, it was necessary to perform a cross that produced an isolate with a disrupted gene that had the opposite mating type from the initial transformants. Isolate 77-15-7 (mat2) was crossed with Tr8.1 to yield isolate 374-14, which had $\triangle N h A B C 1$ and was mat2. Isolate $374-14$ was crossed with Tr18.5 ( $\triangle P D A 1)$ to yield isolates beginning with the number 375. Tr18.5 had the disrupted $P D A 1$ gene but retained the CD chromosome with the PEP genes and the genes for homoserine utilization (Rodriguez-Carres et al. 2008). Thus, the presence of the CD chromosomes in PDA ascospores was determined by scoring for the ability to use homoserine as a carbon source. Isolates 375-1, 375-9, 375-13, and 375-19 were all $\triangle \mathrm{NhABC} 1 ; \triangle \mathrm{PDA} 1$ and carried the CD chromosome. These double mutants displayed similar phenotypes in the pea virulence assay (Table 2) and the radial growth pisatin-tolerance assay (Table 1; Fig. 2; data not shown), therefore limiting the possibility that the observed phenotypes (i.e., reduced virulence and enhanced pisatin sensitivity) are due to an unknown recombination event during meiosis. Since all isolates were similar, only isolate $375-13$ was used in subsequent characterization assays.

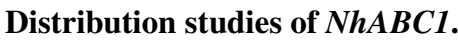

Genomic DNA of fungi was extracted as described above, and $4 \mu \mathrm{g}$ were digested with EcoRI. The DNA was transferred to Hybond TM-N+ membrane (Amersham Pharmacia Biotech, Ltd). Southern hybridizations were conducted using the approximately 500-bp PCR fragment of $N h A B C 1$ described above, and washes were carried out under high stringency conditions as described above.

\section{In vitro expression studies.}

Isolate 77-13-7 was grown overnight on a rotary shaker in PDB as described above and (+) pisatin (in DMSO) was added to a final concentration of $90 \mu \mathrm{g} / \mathrm{ml}$ and $1 \%$ DMSO. Over the next $2 \mathrm{~h}, 15-\mathrm{ml}$ aliquots were removed at various timepoints, and the mycelium was collected by vacuum filtration and was lyophilized and ground to a powder with a mortar and pestle, using liquid nitrogen. Total RNA was extracted from the ground mycelium as described in Mandel and associates (2006) and was suspended in water. Contaminating genomic DNA was removed using DNase (GenHunter, Nashville, TN, U.S.A.), following the manufacture's protocol. cDNA was synthesized using SuperScript II reverse transcriptase (Invitrogen Life Technologies) and oligo-dT primer (Invitrogen Life Technologies), following the manufacturer's protocol.

Quantitative PCR was carried out to measure the induction of $N h A B C 1$ by pisatin in vitro. Transcripts of the $\beta$-actin housekeeping gene were used to normalize the level of $N$. haematococca transcripts. Primers were based on the $3^{\prime}$ end sequences of the genes of interest. The $\beta$-actin sequence was amplified with the primers Actin-F (5'-GTG TGA TGT CGA TGT CCG AAA GG-3') and Actin-R (5'-GAA GAA GGA GCA AGA GCA GTA ATC- $3^{\prime}$ ) and $N h A B C 1$ with the primers NhABC1-F (5'-CTC CAG CTA CGA CAA CCG AT- $3^{\prime}$ ) and NhABC1-R (5'-TGT CTA CGA CTG CTT CTG CTT CT-3').

Each reaction had a total volume of $25 \mu$ l containing $12.5 \mu \mathrm{l}$ of Platinum quantitative PCR supermix-UDG (containing Platinum Taq DNA polymerase, Tris- $\mathrm{HCl}, \mathrm{KCl}, 6 \mathrm{mM} \mathrm{MgCl}$, $400 \mu \mathrm{M}$ dGTP, $400 \mu \mathrm{M}$ dATP, $400 \mu \mathrm{M}$ dCTP, $800 \mu \mathrm{M}$ dUTP, and UDG [uracil DNA glycosylase] [Invitrogen Life Technologies] and stabilizers), $250 \mathrm{nM}$ forward primer, $250 \mathrm{nM}$ reverse primer, $500 \mathrm{nM}$ Rhodamine $X$ reference dye, $2 \mu \mathrm{l}$ cDNA template, and $9 \mu \mathrm{l}$ of sterile distilled water. The PCR parameters were an initial uracil-N-glycosylase step at $50^{\circ} \mathrm{C}$ for $2 \mathrm{~min}$, followed by an initial denaturation and Platinum Taq DNA polymerase activation step at $95^{\circ} \mathrm{C}$ for $10 \mathrm{~min}$ and 40 cycles at $95^{\circ} \mathrm{C}$ for $15 \mathrm{~s}$ and $60^{\circ} \mathrm{C}$ for $30 \mathrm{~s}$. Real-time PCR for each gene was performed at least three times. An ABI PRISM 7300 sequence detection system (Applied Biosystems, Foster City, CA, U.S.A.) was used, and the data were compared using the algorithm $x=2^{-\Delta \Delta \mathrm{Ct}}$ as previously described (Livak and Schmittgen 2001).

\section{Expression of $N$. haematococca genes in infected pea pods.}

Expression studies on $N$. haematococca MPVI PDAl and $N h A B C 1$ were performed as described by Wagoner and associates (1982). Spores of 77-13-4 were obtained from 1- to 2week-old V8 juice agar medium, were rinsed with sterile water, and were suspended in sterile water at a concentration of $5 \times$ $10^{6}$ spores per milliliter. Immature pea pods (Sugar Snap peas; Mann Packing Co. Inc., Salinas, CA, U.S.A.) of uniform size (approximately 4 to $5 \mathrm{~cm}$ long) were surface-sterilized in $70 \%$ ethanol for $5 \mathrm{~min}$ in a $2.5 \%$ sodium hypochlorite solution for $10 \mathrm{~min}$. and were then rinsed thoroughly with sterile distilled water. Pea pods then were halved, deseeded, and placed into 60-mm diameter petri plates. The freshly exposed endocarp tissue was inoculated with $1 \mathrm{ml}$ of spore suspension and was incubated at $24^{\circ} \mathrm{C}$. Challenged pea endocarp tissue was re- 
moved at $0,1,2,3,9,12,24,36$, and $48 \mathrm{~h}$ postinoculation by scraping off the surface layers using a metal spatula, was immediately immersed in liquid nitrogen, and was frozen at $-80^{\circ} \mathrm{C}$.

Total RNA was extracted using Trizol (Invitrogen Life Technologies) and was treated with DNase (GenHunter), and cDNA was synthesized as above, using Superscript II reverse transcriptase and oligo dT primer. Quantitative real-time PCR was used to measure the induction of NhABC1 and PDAl in infected pea tissue, as mentioned above, with the following exceptions. NhABC1 transcripts were amplified with the primers ABC77134-F (5'-ATC CTG TTG GCT TCC ACA AG-3') and ABC77134-R (5'-AAC TGC CAG AAC AGA AGC CA-3'). PDA1 transcripts were amplified with the primers PDA1F $\left(5^{\prime}\right.$ CCC GAG GGT ACT GAG GTT G-3') and PDA1R (5'-GAT GCT GAT GTT CTT GCC-3') (Liu et al. 2003). Erg gene transcripts, used to normalize the level of $N$. haematococca transcripts, were amplified with the primers Erg1F (5'-CAG TAC AAG ATG CCC AGA GCT-3') and Erg1R (5'-TGT GCC ACA GAG TAG GAA AGT C-3').

\section{Analysis of pisatin production in infected pea pods.}

Pea-pod inoculation with $N$. haematococca isolate 77-13-4 and tissue harvesting was performed as described above. Pisatin was extracted from the tissue adjacent to the site of infection by immersing the tissue in hexanes $(10 \mathrm{ml} / \mathrm{g})$ and incubating the immersed pods on a gyratory shaker $(130 \mathrm{rpm})$ at $24^{\circ} \mathrm{C}$ for $16 \mathrm{~h}$. The tissue was removed, the hexanes were evaporated, and the residue was dissolved in $1 \mathrm{ml}$ of ethanol, and pisatin was quantified as previously described (Wu and VanEtten 2004).

\section{Pathogenicity assays.}

The pea "test tube" lesion and carrot pathogenicity assays were conducted as previously described (Funnell and VanEtten 2002; Wasmann and VanEtten 1996). Pisum sativum cv. Alaska 2B (Carolina Biological Supply Co., Burlington, NC, U.S.A.), and organically grown carrots were used for the virulence assays.

\section{Spore germination assay.}

Macroconidia from 4-day-old V-8 juice agar medium were added to $500 \mu \mathrm{l}$ of PDB in an Eppendorf tube to a final concentration of $10^{5}$ spores per milliliter. Pisatin was added to a final concentration of $180 \mu \mathrm{g} / \mathrm{ml}$ in $1 \%$ DMSO, and cultures were incubated at room temperature on a rotary shaker at 120 rpm. Samples were taken for microscopy, and spore germination was calculated by measuring the percentage of spores (out of at least 100) that had germinated. A spore was considered germinated if the germ-tube length was larger than the diameter of the spore (VanEtten and Stein 1978).

\section{Antimicrobial growth assays.}

Radial growth on Martin's agar medium (Stevens 1974) containing (+) pisatin or other compounds was used to measure the sensitivity to these compounds of the wild type and mutants of $N$. haematococca. The protocol used was as previously described (Delserone et al. 1999), except that one-week-old cultures were used for the inoculum and three replications were used for each treatment. Sensitivity to the different compounds is reported as percent inhibition of radial growth on a medium containing the compounds compared with the control treatment when the growth reaches the edge of the plate. The following compounds (at the concentrations shown) were dissolved in DMSO, except when $\mathrm{H}_{2} \mathrm{O}$ is indicated, to give a final DMSO concentration of 1\%: amphotericin B $(35 \mu \mathrm{g} / \mathrm{ml}$; Sigma, St. Louis), anoymidol (EL-531, $20 \mu \mathrm{g} / \mathrm{ml}$; Eli Lilly,
Indianapolis, IN, U.S.A.), benomyl (20 $\mu \mathrm{g} / \mathrm{ml}$; DuPont, Wilmington, DE, U.S.A.), benzimdazole $(20 \mu \mathrm{g} / \mathrm{ml}$; Sigma), benzoic acid $(20 \mu \mathrm{g} / \mathrm{ml}$; Sigma), berberine chloride $(40 \mu \mathrm{g} / \mathrm{ml}$; Sigma), bialophos (10 $\mu \mathrm{g} / \mathrm{ml}$; Sigma), brefeldin A $(10 \mu \mathrm{g} / \mathrm{ml}$; Sigma), carbenacillin $(200 \mu \mathrm{g} / \mathrm{ml}$; Sigma), cefotoxin $(350$ $\mu \mathrm{g} / \mathrm{ml}$; Sigma), $\alpha$-chaconine ( $20 \mu \mathrm{g} / \mathrm{ml}$; Sigma), chloramphenicol $\left(150 \mu \mathrm{g} / \mathrm{ml}\right.$; Sigma), coumestrol $(20 \mu \mathrm{g} / \mathrm{ml}), \mathrm{CuSO}_{4}(50$ $\mu \mathrm{g} / \mathrm{ml}$, in $\mathrm{H}_{2} \mathrm{O}$; Sigma), cyclohexamide (30 $\mu \mathrm{g} / \mathrm{ml}$; Sigma), doxorubicin (15 $\mu \mathrm{g} / \mathrm{ml}$; Sigma), etaconazole $(20 \mu \mathrm{g} / \mathrm{ml})$, ethidium bromide $\left(5 \mu \mathrm{g} / \mathrm{ml}\right.$, in $\mathrm{H}_{2} \mathrm{O}$; Sigma), fenarimol (EL222, $25 \mu \mathrm{g} / \mathrm{ml}$; Eli Lilly), 5-fluorouracil (10 $\mu \mathrm{g} / \mathrm{ml}$; Sigma), gossypol $(20 \mu \mathrm{g} / \mathrm{ml}), 8$-hydroxyquinoline (100 $\mu \mathrm{g} / \mathrm{ml}$; Sigma), imazalil $(5 \mu \mathrm{g} / \mathrm{ml})$, ketoconazole $(50 \mu \mathrm{g} / \mathrm{ml}$; Sigma), kievitone (20 $\mu \mathrm{g} / \mathrm{ml})$, miconazole (30 $\mu \mathrm{g} / \mathrm{ml}$; Sigma), nuarimol (EL-228, $20 \mu \mathrm{g} / \mathrm{ml}$; Eli Lilly), nystatin $(20 \mu \mathrm{g} / \mathrm{ml}$, Sigma), ononin (20 $\mu \mathrm{g} / \mathrm{ml}$, Indofine, Hillsborough, NJ, U.S.A.), phaseollin (20 $\mu \mathrm{g} / \mathrm{ml}),(+)$ pisatin $(90$ and $180 \mu \mathrm{g} / \mathrm{ml}),(-)$ pisatin $(50 \mu \mathrm{g} / \mathrm{ml})$, propiconazole $(20 \mu \mathrm{g} / \mathrm{ml}$; Sigma), resveratrol $(200 \mu \mathrm{g} / \mathrm{ml}$; Sigma), rhodamine $6 \mathrm{G}(10 \mu \mathrm{g} / \mathrm{ml}$; Sigma $)$, rishitin $(200 \mu \mathrm{g} / \mathrm{ml}$; a gift from S. P. McCormick, United States Department of Agriculture, Peoria, IL, U.S.A.), safrole (1 $\mathrm{mg} / \mathrm{ml}$; Sigma), sesamol (50 $\mu \mathrm{g} / \mathrm{ml}$; Sigma), sodium azide $\left(30 \mu \mathrm{g} / \mathrm{ml}\right.$, in $\mathrm{H}_{2} \mathrm{O}$; Sigma), sodium cyanide $\left(30 \mu \mathrm{g} / \mathrm{ml}\right.$, in $\mathrm{H}_{2} \mathrm{O}$; Sigma), $\alpha$-solanine $(20 \mu \mathrm{g} / \mathrm{ml}$; Sigma), (+) taxifolin $(20 \mu \mathrm{g} / \mathrm{ml}$; Sigma $)$, tomatine $(20 \mu \mathrm{g} / \mathrm{ml}$; Spectrum, Gardena, CA, U.S.A.), triarimol (EL-273, $20 \mu \mathrm{g} / \mathrm{ml}$; Eli Lilly), and (+) verapamil $(25 \mu \mathrm{g} / \mathrm{ml}$; Sigma). Several phytoalexins (coumestrol, gossypol, kievitone, phaseollin, (+) pisatin, and (-) pisatin) were isolated as previously described (George and VanEtten 2001) or were from laboratory stocks, unless noted otherwise. Antimicrobial growth assays were performed once, except for $(+)$ pisatin, which was assayed three times at the $90-\mu \mathrm{g} / \mathrm{ml}$ concentration and twice at the $180-\mu \mathrm{g} / \mathrm{ml}$ concentration. Except for (+) pisatin, (-) pisatin, and rishitin, all the other compounds did not inhibit the radial growth of $\operatorname{Tr} 8.1(\triangle \mathrm{NhABC} 1)$ more than $10 \%$, as compared with the wild type.

\section{Phylogenetic analysis of NhABC1 and similar proteins.}

The predicted amino acid sequences of other fungal $\mathrm{ABC}$ transporters with high sequence similarity to $\mathrm{NhABC} 1$ were identified by BLASTp searches to the fungal genomes available from National Center for Biotechnology Information and the Fungal Genome Initiative of the Broad Institute. Sequences were aligned and manually edited using ClustalW 1.81 and MacClade 4.08 as previously described (Coleman et al. 2009). Phylogenetic analyses for maximum parsimony and maximum likelihood were conducted employing PAUP* 4.0 (Swafford 1999).

\section{ACKNOWLEDGMENTS}

We thank S. P. McCormick for the generous gift of rishitin and $\mathrm{R}$. Celoy for quantification of extracted pisatin. J. J. Coleman would especially like to thank E. Temporini and C. Wasmann for experimental advice. Funding was provided by the National Science Foundation (grant number MCB-0641808 to H. D. VanEtten).

\section{LITERATURE CITED}

Coleman, J. J., and Mylonakis E. 2009. Efflux in fungi: La pièce de résistance. PLoS Pathog. 5: e1000486. Published online.

Coleman, J. J., Rounsley, S. D., Rodriguez-Carres, M., Kuo, A., Wasmann, C. C., Grimwood, J., Schmutz, J., Taga, M., White, G. J., Zhou, S. Schwartz, D. C., Freitag, M., Ma, L.-J., Danchin, E. G., Henrissat, B., Coutinho, P. M., Nelson, D. R., Straney, D., Napoli, C. A., Barker, B. M., Gribskov, M., Rep, M., Kroken, S., Molnár, I., Rensing, C., Kennell, J. C., Zamora, J., Farman, M. L., Selker, E. U., Salamov, A., Shapiro, H., Pangilinan, J., Lindquist, E., Lamers, C., Grigoriev, I., Geiser, D. M., Covert, S. F., Temporini, E., and VanEtten, H. D. 2009. The genome 
of Nectria haematococca: Contribution of supernumerary chromosomes to gene expansion. PLoS Genet. 5:e1000618. Published online.

Covert, S. F. 1998. Supernumerary chromosomes in filamentous fungi. Curr. Genet. 33:311-319.

Cruickshank, I. A. M. 1962. Studies on phytoalexins. IV. The antimicrobial spectrum of pisatin. Aust. J. Biol. Sci. 15:147-159.

Cruickshank, I. A. M. 1965. Phytoalexins in the leguminosae with special reference to their selective toxicity. Tagungsber. Dtsch. Akad. Landwirtschaftswiss Berlin 74:313-332.

Cruickshank, I. A. M., and Perrin, D. R. 1960. Isolation of a phytoalexin from Pisum-sativum L. Nature 187:799-800.

Cruickshank, I. A. M., and Perrin, D. R. 1965. Studies on phytoalexins VIII. The effect of some further factors on the formation stability and localization of pisatin in vivo. Aust. J. Biol. Sci. 18:817-828.

Delserone, L. M., McCluskey, K., Matthews, D. E., and VanEtten, H. D. 1999. Pisatin demethylation by fungal pathogens and nonpathogens of pea: Association with pisatin tolerance and virulence. Physiol. Mol. Plant Pathol. 55:317-326.

Denny, T. P., and VanEtten, H. D. 1981. Tolerance by Nectria haematococca MPVI of the chickpea (Cicer arietinum) phytoalexins medicarpin and maackiain. Physiol. Plant Pathol. 19:419-437.

Denny, T. P., and VanEtten, H. D. 1983a. Tolerance of Nectria haematococca MP VI to the phytoalexin pisatin in the absence of detoxification. J. Gen. Microbiol. 129:2893-2901.

Denny, T. P., and VanEtten, H. D. 1983b. Characterization of an inducible, nondegradative tolerance of Nectria haematococca MP VI to phytoalexins. J. Gen. Microbiol. 129:2903-2913.

Denny, T. P., Matthews, P. S., and VanEtten, H. D. 1987. A possible mechanism of nondegradative tolerance of pisatin in Nectria haematococca MPVI. Physiol. Mol. Plant Pathol. 30:93-107.

Desjardins, A. E., and Gardner, H. W. 1989. Genetic analysis in Gibberella pulicaris: Rishitin tolerance, rishitin metabolism, and virulence on potato tubers. Mol. Plant-Microbe Interact. 2:26-34.

Fleissner, A., Sopalla, C., and Weltring, K. M. 2002. An ATP-binding cassette multidrug-resistance transporter is necessary for tolerance of Gibberella pulicaris to phytoalexins and virulence on potato tubers. Mol. Plant-Microbe Interact. 15:102-108.

Funnell, D. L., and VanEtten, H. D. 2002. Pisatin demethylase genes are on dispensable chromosomes while genes for pathogenicity on carrot and ripe tomato are on other chromosomes in Nectria haematococca. Mol. Plant-Microbe Interact. 15:840-846.

George, H. L., and VanEtten, H. D. 2001. Characterization of pisatininducible cytochrome P450s in fungal pathogens of pea that detoxify the pea phytoalexin pisatin. Fungal Genet. Biol. 33:37-48.

Han, Y., Liu, X. G., Benny, U., Kistler, H. C., and VanEtten, H. D. 2001 Genes determining pathogenicity to pea are clustered on a supernumerary chromosome in the fungal plant pathogen Nectria haematococca. Plant J. 25:305-314

Higgins, C. F. 2007. Multiple molecular mechanisms for multidrug resistance transporters. Nature 446:749-757.

Kistler, H. C., and VanEtten, H. D. 1984. Three non-allelic genes for pisatin demethylation in the fungus Nectria haematococca. J. Gen Microbiol. 130:2595-2603.

Kovalchuk, A., and Driessen, A. J. M. 2010. Phylogenetic analysis of fungal ABC transporters. BMC Genomics 11:177.

Liu, X. G., Inlow, M., and VanEtten, H. D. 2003. Expression profile of pea pathogenicity $(P E P)$ genes in vivo and in vitro, characterization of the flanking regions of the $P E P$ cluster and evidence that the $P E P$ cluster region resulted from horizontal gene transfer in the fungal pathogen Nectria haematococca. Curr. Gent. 44:95-103.

Livak, K., and Schmittgen, T. 2001. Analysis of relative gene expression data using real-time quantitative PCR and the $2^{-\Delta \Delta C t}$ method. Methods 25:402-408

Mandel, M. A., Galgiani, J. N., Kroken, S., and Orbach, M. J. 2006. Coccidiodes posadasii contains single chitin synthase genes corresponding to classes I to VII. Fungal Genet. Biol. 43:775-788.

Miao, V. P. W., Covert, S. F., and VanEtten, H. D. 1991a. A fungal gene for antibiotic resistance is on a dispensable ("B") chromosome. Science 254:1773-1776.
Miao, V. P. W., Matthews, D. E., and VanEtten, H. D. 1991b. Identification and chromosomal locations of a family of cytochrome P-450 genes for pisatin detoxification in the fungus Nectria haematococca. Mol. Gen. Genet. 226:214-223.

Morrissey, J. P., and Osbourn, A. E. 1999. Fungal resistance to plant antibiotics as a mechanism of pathogenesis. Microbiol. Mol. Biol. Rev. 63:708-724.

Müller, K. O., and Börger, H. 1940. Experimentelle Untersuchungen iiber die Phythophthora-Kesistenz der Kartoffel. Zugleich ein Beitrag zum Problem der "erworbenen Resistenz" im Pflanzenreich. Arbeiten Biol. Reichsanstalt Land und Forstwirtschaft 23:189-231.

Pedras, M. S. C., and Ahiahoun, P. W. K. 2005. Metabolism and detoxification of phytoalexins and analogs by phytopathogenic fungi. Phytochemistry 66:391-411.

Pezet, R., Pont, V., and Hoang-Van, K. 1991. Evidence for oxidative detoxification of pterostilbene and resveratrol by a laccase-like stilbene oxidase produced by Botrytis cinerea. Physiol. Mol. Plant Pathol. 39:441-450.

Rissler, J. F., and Miller, R. L. 1977. Contribution of a cyanide-insensitive alternative respiratory system to increases in formamide hydro-lyase activity and to growth in Stemphylium loti in vitro. Plant Physiol. 60:857-861.

Rodriguez-Carres, M., White G., Tsuchiya, D., Taga, M., and VanEtten, H. D. 2008. The supernumerary chromosome of Nectria haematococca that carries pea-pathogenicity-related genes also carries a trait for pea rhizosphere competitiveness. Appl. Environ. Microbiol. 74:3849-3856.

Sanwal, H., Panwar, S. L., and Prasad, R. 2009. ATP-binding cassette $(\mathrm{ABC})$ transporters in yeasts: Their role in multidrug resistance and survival. Pages 149-179 in: ABC Transporters in Microorganisms: Research innovation and value as targets against drug resistance. A. PonteSucre, ed. Academic Press, Norfolk, U.K.

Schoonbeek, H., Del Sorbo, G., and De Waard, M. A. 2001. The ABC transporter BcatrB affects the sensitivity of Botrytis cinerea to the phytoalexin resveratrol and the fungicide fenpiclonil. Mol. Plant-Microbe Interact. 14:562-571.

Stevens, R. B. 1974. Mycology Guidebook. University of Washington Press, Seattle, WA, U.S.A.

Swafford, D. L. 1999. PAUP* Phylogenic Analysis Using Parsimony (*and other methods). 4th ed. Sinauer Associates, Inc., Sunderland, MA, U.S.A.

Uehara, K. 1964. Relationship between host specificity of pathogens and phytoalexin. Ann. Phytopathol. Soc. Jpn. 29:103-110.

Urban, M., Bhargava, T., and Hamer, J. E. 1999. An ATP-driven efflux pump is a novel pathogenicity factor in rice blast disease. EMBO (Eur. Mol. Biol. Organ.) J. 18:512-521.

VanEtten, H. D., and Barz, W. 1981. Expression of pisatin demethylating ability in Nectria haematococca. Arch. Microbiol. 129:56-60.

VanEtten, H. D., and Stein, J. I. 1978. Differential response of Fusarium solani isolates to pisatin and phaseollin. Phytopathol. 68:1276-1283.

VanEtten, H. D., Matthews, P. S., Tegtmeier, K. J., Dietert, M. F., and Stein, J. I. 1980. The association of pisatin tolerance and demethylation with virulence on pea in Nectria haematococca. Physiol. Plant Pathol. 16:257-268.

VanEtten, H., Temporini E., and Wasmann, C. 2001. Phytoalexin (and phytoanticipin) tolerance as a virulence trait: Why is it not required by all pathogens? Physiol. Mol. Plant Pathol. 59:83-93.

Wagoner, W., Loschke, D. C., and Hadwiger, L. A. 1982. Two-dimensional electrophoretic analysis of in vivo and in vitro synthesis of proteins in peas inoculated with compatible and incompatible Fusarium solani. Physiol. Plant Pathol. 20:99-107.

Wasmann, C. C., and VanEtten, H. D. 1996. Transformation-mediated chromosome loss and disruption of a gene for pisatin demethylase decrease the virulence of Nectria haematococca on pea. Mol. Plant-Microbe Interact. 9:793-803.

$\mathrm{Wu}, \mathrm{Q}$., and VanEtten, H. D. 2004. Introduction of plant and fungal genes into pea (Pisum sativum L.) hairy roots reduces their ability to produce pisatin and affects their response to a fungal pathogen. Mol. Plant-Microbe Interact. 17:798-804. 